\title{
Fast efficient computation of expected value of sample information from a probabilistic sensitivity analysis sample: a non-parametric regression approach
}

\author{
Mark Strong*, Alan Brennan, Jeremy Oakley \\ From 2nd Clinical Trials Methodology Conference: Methodology Matters \\ Edinburgh, UK. 18-19 November 2013
}

Health economic models are used to estimate the expected net benefits of competing decision options. The true values of the parameters of such models are rarely known with certainty, and it is often useful to quantify the value of undertaking further data collection (e.g. a future trial) in order to reduce uncertainty. The value of a proposed future trial can be quantified by its Expected Value of Sample Information (EVSI).

The standard approach to computing EVSI is via a nested two-level Monte Carlo sampling scheme that typically requires a large number of economic model runs. This is problematic for complex models, particularly those that require for each model run a large number of patientlevel simulation steps. An additional problem arises if the EVSI inner loop requires MCMC (i.e. in those cases where the parameter distribution is not conjugate to the likelihood of the simulated trial data). In practice, these difficulties have resulted in the restriction of EVSI analyses to only a small number of published examples.

To overcome the problems above we present novel, fast and efficient non-parametric regression based method for computing EVSI. The method requires only the "probabilistic sensitivity analysis" (PSA) sample: a single set of samples from the model inputs, along with the corresponding set of model evaluations. The new method allows EVSI to be computed for a model of any complexity, and hence be made more widely available to trial designers and decision makers.

We present the method and illustrate its application in a case study.

University of Sheffield, Sheffield, UK

(c) 2013 Strong et al; licensee BioMed Central Ltd. This is an Open Access article distributed under the terms of the Creative Commons Attribution License (http://creativecommons.org/licenses/by/2.0), which permits unrestricted use, distribution, and reproduction in any medium, provided the original work is properly cited.
doi:10.1186/1745-6215-14-S1-O25

Cite this article as: Strong et al:: Fast efficient computation of expected value of sample information from a probabilistic sensitivity analysis sample: a non-parametric regression approach. Trials 2013 14(Suppl 1): $\mathrm{O} 25$.
Submit your next manuscript to BioMed Central and take full advantage of:

- Convenient online submission

- Thorough peer review

- No space constraints or color figure charges

- Immediate publication on acceptance

- Inclusion in PubMed, CAS, Scopus and Google Scholar

- Research which is freely available for redistribution Submit your manuscript at
www.biomedcentral.com/submit C Biomed Central 